\title{
STUDY ON THE LEVEL OF SELF-ESTEEM IN VISUALLY IMPAIRED STUDENTS
}

\author{
Valentin Claudiu LUCA ${ }^{1 *}$, Liliana MIHĂILESCU ${ }^{1}$ \\ ${ }^{1}$ University of Pitești, Physical Education and Sport Department, Pitești, Romania \\ *Corresponding author: lucaclaudiu@yahoo.com
}

DOI: https://doi.org/10.51267/icpesk2020bp07

\begin{abstract}
The purpose of the research was to investigate the level of self-esteem in visually impaired children in order to determine, together with investigations on other levels (health, psychomotor ability, physical development), the level of their quality of life compared to children of the same age without impairments. The self-esteem level was investigated using the Coopersmith Self-Esteem Inventory on a sample of 30 participants from the Special Secondary School for Visually Impaired Students in Bucharest, with an average age of 11 years. The applied test represents a modern psychometric instrument, which has been validated in a variety of research programmes. It helps to better understand the students evaluated regarding their self-esteem by measuring the evaluative attitudes of the self in various planes of their existence. The standard form for students contains five subscales: general perception of self, social self-peers, home-parents, school-academic experience and distortion scale. Following the application of the test, it has been noted that the level of self-esteem of the visually impaired is higher, on average, than that of the average population of Romanian students without visual impairments. Considering the results, some decisions will be made regarding the approach to teaching dancesport to the visually impaired and, at the same time, we will be able to observe how practising this sport can influence the evolution of self-esteem in the visually impaired, as an element of their quality of life.
\end{abstract}

Keywords: self-esteem, visual impairment, dancesport, social inclusion.

\section{Introduction}

Society in general but also the educational and sports systems fail to pay enough attention to people with Special Educational Needs (SEN). This category includes children with: sensory or physical impairments, behavioural and mental disorders, emotional and mood disorders, learning and communication difficulties.

By playing games, practising certain branches of sport, etc., children with visual impairments can gain independence and autonomy, learn things about the environment, learn spatial orientation and socialise.

A person's quality of life is reflected on several levels, one of them being self-esteem.

Self-image refers to the way an individual perceives their own emotional, physical, spiritual, cognitive, and social characteristics. How a person perceives themselves depends on their degree of self-esteem. Thus, self-acceptance and the ability to value the good things done contribute to increasing self-confidence and respect, and the acceptance without exaggerated criticism of weaknesses and mistakes lays the foundations of the idea of tolerance towards oneself and others.

Self-esteem could be defined as the level of general regard that an individual has for themselves as a person (Leary \& Baumeister, 2000). Moreover, self-esteem can play a profound and important role in all aspects regarding a child's development (Brooks, 1992). 
Self-esteem is also defined by the way people value themselves. It represents a component of self-knowledge, an evaluative one. A high level of self-esteem is due to a favourable general self-evaluation. However, self-esteem cannot be measured accurately. High selfesteem may be due to a justified appreciation of personal merits, competencies, successes, but it may also be due to a feeling of superiority over others. About a low self-esteem level, it can be said that it is due to an accurate understanding of one's weaknesses, to a distorted or even a pathological sense of inferiority and insecurity. (Baumeister et al., 2003)

Self-image influences behaviour. A good self-image and high self-esteem help to achieve goals because they give enthusiasm, determination and energy. On the other hand, low selfesteem can lead to a low level of motivation or a complete lack of motivation. The foundations of self-image are laid in childhood, being determined by the balanced attitude of parents. An extremely critical attitude will result in an underestimated self-perception of the child, who will consider themselves insufficiently "good". On the other hand, an extremely permissive attitude, lack of penalties when appropriate and excessive praise lead to an exaggeratedly good self-opinion of the child, in other words, to a completely unrealistic selfimage, which will bring many problems in the future.

Regarding self-esteem in the visually impaired, their attitudes and behaviours, there are a multitude of studies, conducted in several countries, on children and young adolescents, through the use of various assessment tools. The results and conclusions of these studies are obviously different.

Thus, about $70 \%$ of the children scored between a 'normal' and 'high' level of selfesteem. Overall scores for self-esteem were similar both at secondary and primary levels (Bowen, 2010).

Furthermore, Miklyaeva and Gorkovaya (2019) consider that "the hardiness of visually impaired adolescents and its components (commitment, control and challenge) do not differ from similar indicators in the sample of their 'healthy' peers. Probably, the development of ideas about one's own life and relationships with the world happens in accordance with the universal laws of personal formation regardless of the vision status in adolescence." (p. 94).

Another study regarding the level of self-esteem in people with visual impairments compared the self-concept of normally sighted $(n=229)$ and the visually impaired $(n=61)$ American students in grades 6-8. Despite the idea that visually impaired children have a relatively low self-esteem, the study concluded the opposite: visually impaired students have higher self-esteem scores than normally sighted children. (Obiakor \& Stile, 1990)

Tołczyk and Pisula (2019) believe that the lack of significant differences in the global level of self-esteem between groups with and without visual impairments could be the result of access to professional support, rehabilitation and education in the group with impairments. A very important aspect of self-esteem for females with visual impairments seems to be the body appearance - they scored lower than the other groups.

Another study concluded that mental health of visually impaired athletes could be approximately the same as the mental health of non-visually impaired athletes and also of the general population, and be related to gender, stress during competition and support from family members (Kohda et al., 2019). 
However, visually impaired children may have low self-esteem due to the fact that the challenges they have to face are different from those experienced by children without disabilities (Hadidi \& AlKhateeb, 2013).

Also, each country has its own education system and organization. Different investments are made to support people with disabilities, and their level of integration differs. All this can affect the way a child perceives their own psyche or level of self-esteem. (Bracken, 1995)

Saigal et al. (2002) state that children's self-esteem and well-being from a social and emotional point of view are very important areas and should be closely followed in the case of children at high risk of adjustment problems.

Augestad (2017) conducted an extensive study of articles published between 1998 and 2016 on self-esteem in visually impaired children and young adolescents. Thus, the author found 26 publications from 15 countries. Most studies were conducted on a small number of subjects and only 7 of them included more than 100 participants. The conclusion of this study was that 5 of the publications found the self-esteem of visually impaired children as being low or very low compared to children without disabilities, 7 publications did not find significant differences, some of the publications identified positive differences in favour of visually impaired children, and another part of them identified differences by certain age categories. Other major differences found between the studies were related to the influence of the degree of impairment on self-esteem. Thus, two studies state that the severity of visual impairment does not influence self-perception (Huurre et al., 1999; Pinquart \& Pfeiffer, 2013), while four other studies (Bowen, 2010; Garaigordobil \& Bernarás, 2009; Papadopoulos, 2014; Were et al., 2010) emphasise exactly the opposite.

Therefore, there is no clear conclusion regarding the self-esteem of visually impaired children, but all studies seem to indicate, according to Augestad (2017), that friendship, socialisation, parenting and autonomy in movement and various activities have special importance for the way the self is perceived and the level of self-esteem. Leisure activities that involve forms of socialising, possibly with friends, are also considered to be extremely important (Huurre \& Aro, 2000).

Moreover, Griffin-Shirley and Nes (2005) state that the development of self-esteem in visually impaired children can only be achieved in an environment that allows them the freedom to explore without the existence of major dangers. They also emphasise the importance of engaging them in leisure activities adapted and suitable for them.

As regards the importance of the social side of it, the subjects who got more positive social support from their friends experienced fewer depressive symptoms (Papadopoulos \& Papakonstantinou, 2019).

Therefore, from any angle this situation may be viewed, one thing is certain: engaging visually impaired children in sports activities that encourage socialisation and improvement of fitness is auspicious and beneficial not only for the physical side but also for their mental well-being.

The educational system, but also the sport system and society in general faces an acute lack of attention to the impaired. Thus, it is now being increasingly recognised that the problem does not reside in the person with a disability, but results from the structures, practices and attitudes that prevent the individual from exercising their capabilities (Dawn, 2018). 
High levels of physical activity that provide health-related benefits for children and youths with visual impairments are possible. According to the World Health Organization (WHO), physical inactivity is a considerable health problem. (Giese et al., 2017)

As concerns people with impairments, the problem with doing exercise is looked upon as the method and means to diminish the negative consequences that the impairment has on the individual's personality development (Pelin et al., 2016). The more so as the sport might contribute to a significant decrease in anxiety, so present in people with visual impairments: anxiety disorders are more frequent among people with visual impairments than in normally sighted people (Binder-Olibrowska et al., 2018).

As regards the therapeutic function of doing dancesport, it is stated that the use of dance as a healing tool is rooted in the knowledge that body and mind are inseparable; dance provides a direct experience of shared emotion on a preverbal and physical level, providing feelings of unity, harmony and empathy (Samson, 2017).

In conclusion, our results suggest the importance of perception of physical competence and self-esteem in adolescent boys and girls. These issues should be addressed and promoted in physical education classes to improve fitness and body satisfaction with the appropriate methodology and approach. (Sánchez-Miguel et al., 2020)

\section{Research problem}

The quality of life of people with disabilities, in general, and those with visual impairments, in particular, is an important issue and a social concern, and the sport valences in the social integration of the population category are well known. Self-esteem is an essential component of the quality of life, defines the psychological profile and decisively contributes to the individual's social integration.

Practising sports should be a matter of normalcy for every individual, without exception. Nonetheless, for people with visual impairments, things are unfortunately not exactly simple. For them, practising sport branches involves adaptations from both the methodological perspective and as regards the materials, performance space, etc. However, investments need to be made in this sense for the individuals with this type of impairment to be able to lead an active social life, to work and to provide for themselves. The need of doing one sport is all the greater as the complete or partial visual impairment is coupled with a number of additional problems: serious postural disorders, insufficiently developed muscles, relatively decreased lung capacity, predisposition to depression, low levels of self-esteem or, quite the opposite, excessively high self-esteem as a result of overprotection.

This study consists of an ascertaining research on the self-esteem level of a group of 30 participants from the Special Secondary School for Visually Impaired Students in Bucharest, with an average age of 11 years. The research results aim at lying the basis for the implementation of teaching strategies and they will be the starting point for potential more indepth studies on the psychological needs of people with visual impairments, but also on how these aspects can be influenced by doing a sport. This might lead to a much better guided working manner and approach to sport activity.

\section{Research purpose}


The purpose of the research is to determine the general self-esteem level, but also the values of the four areas investigated in our subjects: Home-Parents (HP), General Perception of Self (GP), Social Self-Peers (SSP), School-Academic Experience (SAE) and Distortion Scale (DS), as an objective benchmark in the development of teaching strategies for teaching dance to children with visual impairments in order to improve their quality of life.

\section{Research hypothesis}

Knowing the level and structure of self-esteem in the investigated areas creates some objective premises to develop an effective teaching strategy for the practice of dancesport by this category of children with SEN in order to increase their quality of life.

\section{Methodology}

\section{Research methods}

To achieve the purpose, the following research methods were used: bibliographical study; pedagogical observation; questionnaire survey - test method; statistical and mathematical method.

\section{Participants}

In order to achieve the research purpose and objectives, a series of administrative and research steps were required: the research subjects were established - 30 participants from the Special School for Visually Impaired Students; agreements for participation in the research were submitted to and signed by the subjects' parents.

\section{Content}

The research consisted in finding the self-esteem level of the subjects (RS) compared to the national reference benchmarks for children of the same age without SEN (NS). The result analysis was performed based on descriptive statistics and by applying the Student's t-test.

The Coopersmith Self-Esteem Inventory (School Form) consists in applying a set of 58 questions, 50 of them related to self-esteem and 8 to a Distortion (Lie) Scale (a manner of assessing the defensive way in which a student responds to this instrument). In the end, scores are calculated for the following areas: Total Score (T), Home-Parents (HP), General Perception of Self (GP), Social Self-Peers (SSP), School-Academic Experience (SAE) and Distortion Scale (DS).

\section{Results}

The results are interpreted and analysed compared to the national average obtained from the application of this test. Out of the 30 students, 2 could not answer the questions, therefore the results presented below refer to the remaining 28 subjects. 
Table 1 shows the statistical and mathematical indicators divided by research areas.

Table 1. Statistical and mathematical indicators determined in the RS-NS comparative analysis and divided by the areas in the Coopersmith Self-Esteem Inventory (School Form)

\begin{tabular}{lcccccccc}
\hline \multirow{2}{*}{$\begin{array}{c}\text { Studied } \\
\text { areas }\end{array}$} & \multicolumn{9}{c}{ Average } & \multicolumn{9}{c}{ Statistical and mathematical indicators } \\
& RS & NS & RS & NS & RS & NS & t-test & Threshold \\
& 18.53 & 17.14 & 4.5 & 4.95 & 0.24 & 0.28 & 1.641 & 0.112 \\
\hline GP & 5.75 & 5.88 & 1.4 & 1.92 & 0.24 & 0.32 & -0.49 & 0.628 \\
SSP & 6.75 & 4.94 & 1.93 & 2.2 & 0.28 & 0.44 & 4.94 & 0.000001 \\
HP & 6.6 & 5.38 & 1.54 & 2.18 & 0.23 & 0.40 & 4.195 & 0.000001 \\
SAE & 73.57 & 67.34 & 20.44 & 17.37 & 0.27 & 0.25 & 1.613 & 0.118 \\
T & 3.42 & 4.53 & 1.47 & 2.1 & 0.42 & 0.46 & -3.947 & 0.001 \\
DS & & & & & & & & \\
\hline
\end{tabular}

The test results can be summarised as follows:

a) The RS group has higher overall self-esteem - T - than the NS average. The coefficient of variation shows that both groups (RS and NS) are relatively heterogeneous in this area. 24 of the RS $(85.7 \%)$ got higher scores than the average of the Romanian sample and only 4 of them $(14.3 \%)$ had lower scores;

b) As regards the GP, the high coefficient of variation shows that both the RS and NS are relatively heterogeneous groups. This is an area where the results are slightly more balanced: 18 of the RS (64.3\%) scored above the NS average compared to 10 of them (35.7\%) who reached scores below the benchmark;

c) For the SSP area, the two groups recorded high coefficients of variation, the RS being a relatively heterogeneous group, and the NS, a heterogeneous group. $71.4 \%$ of the RS (20) scored above the NS average in this area;

d) As regards the $\mathrm{CP}$ area, the coefficient of variation shows that we are dealing with a relatively heterogeneous group in the case of the RS and with a heterogeneous group in the case of the NS. $92.8 \%$ of the RS scored higher than the NS average, while only 2 of them (7.2\%) scored lower;

e) As regards the SAE area, both groups got high coefficients of variation, the RS being labelled as a relatively homogeneous group, and the NS being a clearly heterogeneous group. $78.6 \%$ of the RS scored higher than the national benchmarks and only $21.4 \%$ of them scored below this average;

f) As regards the Distortion Scale, the coefficients of variation show that both the NS and RS are heterogeneous groups. $71.4 \%$ of the RS scored lower than the NS average.

In order to find whether the difference between the results obtained by the research subjects and the ones obtained by the national sample was significant, we applied the Student's t-test. Thus:

a) The differences between the NS average and the RS average proved to be statistically significant in the CP, SAE and DS areas (Figure 1). In terms of the CP, the high score shows that students feel loved and understood by their families. In the case of the SAE, the high score shows that students do not feel discouraged by the school activities and are proud of their academic achievements. All these may also be due to the fact that the school environment and the home environment are quite different in the case of the RS compared to 
the NS. Children with visual impairments enjoy much more encouragement, praise and validation from both their families and schools than children in public schools. A low score for the Distortion Scale indicates that the assessed subjects do not show any behaviour of resistance to answers, and their choice is not made from the social desirability perspective.

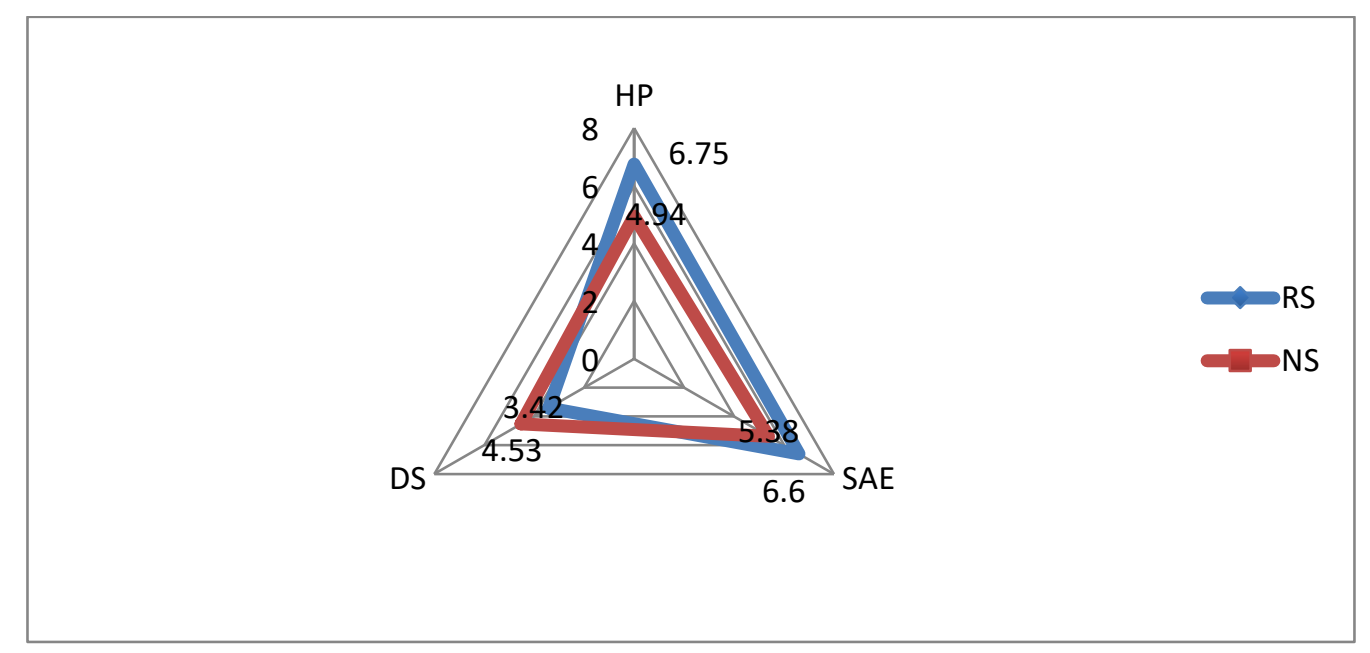

Figure 1. Representation of the significant differences between RS and NS in the CP, DS and SAE areas

b) The differences between the RS average and the NS average are statistically insignificant in terms of the T, GP and SSP.

The RS scored a higher $\mathrm{T}$ result than the NS. People achieving high scores tend to perceive themselves as being capable, significant, successful in life and worthy. They believe they lead satisfactory and gratifying lives. However, the difference is not statistically significant. In terms of the GP, students who score low are self-confident and feel good about themselves. The RS scored higher, on average, than the NS, the difference being statistically insignificant, though. As concerns the SSP, a low score, such as the one obtained by the RS compared to the NS, indicates a lack of interaction and isolation from peers. This is justified when the RS learn in classrooms with fewer students, and the interaction between them is, more often than none, intermediated by teachers. However, the difference is not statistically significant.

\section{Conclusion}

When beginning the self-esteem testing in students with visual impairments, they were expected to obtain lower results than the national average obtained by public school students. The results were however different, since the RS obtained results showing a generally high level of self-esteem, as the results for the T, GP, CP, SAE and DS areas were higher than the ones obtained by the NS.

We consider that the obtained results, most of which are better for the RS, are due to the different environment where they develop compared to children without SEN. The latter live in an open environment and face a variety of challenges, some of which may be highly 
stressful, and the way they deal with those challenges determines their levels of selfconfidence and self-esteem. Students with visual impairments though live in a much more restricted environment from the perspective of their freedom of movement, number and diversity of contacts with people and living situations. Therefore, their direct confrontation with strangers and unusual situations is pretty clear. All the requirements concerning them are made from the perspective of the fact that they "must" be appropriately protected and treated: with low expectations (sometimes, even exaggeratedly low) from their families, with almost round-the-clock aid. Their families oftentimes believe "they cannot do it" and they do it in their stead by postponing, sometimes for an unnaturally long time, granting the independence permission that some children ask for, while others are too anxious to claim and assume it. Schools work hard at nurturing them to gain their independence and do it under controlled conditions, logistically facilitating the passage from one stage to the next.

Children with visual impairments enjoy much more encouragement, praise and validation from both their families and schools than children in public schools. Under these circumstances, the "Unit of Measurement" for self-esteem is different between unimpaired children and visually impaired children. This is how the high scores reached by children with impairments can be explained, as compared to the ones without impairments.

The research outlines an image of the level of self-esteem in visually impaired students aged about 11 years in Romania. There is research in this direction conducted in other countries but, in our country, it is a somewhat less studied field. It is useful to conduct local studies because cultural, social and organizational differences make studies in other areas a good starting point, but not necessarily a landmark to which we can relate our subjects.

It is necessary for us to understand on a large scale students with SEN, in general, and visually impaired children, in particular, to be able to lay the foundations of an open education system, which offers opportunities for the development and affirmation of these people. Sport is an area that also needs adjustment and attention given to students with SEN. Their chances for a higher quality of life increase exponentially with the creation of a system conducive to their development. Students with visual impairments have a number of postural problems that may prevent them from performing natural, everyday tasks. There is a tendency to pay more attention to the physical side of visually impaired students, but at the same time their mental and emotional state must be taken into account, as it influences their quality of life to an even greater extent. A precarious emotional state decreases the level of motivation, desire, and confidence in success, which ultimately leads to the impossibility of improving physical condition. Solutions must therefore be found to address the two aspects concurrently, and this can be easily achieved by practising certain forms of physical activity or sports adapted to the needs and possibilities of this category of students. Their inclusion in such activities will simultaneously achieve both an increase in motor skills and the inclusion of these students in new and varied environments, in a relaxed, playful context, which will facilitate socialisation, exteriorisation, etc. Self-confidence, courage, self-esteem are brought to an optimal level for the healthy development of visually impaired students through the practice of sport, which increases competitiveness, determination, but also educates the acceptance of failure as a new starting point to a higher level of the self.

Practising dancesport is a beneficial opportunity to experiment and learn new things. It puts the visually impaired in the position to boost their self-confidence and different ways, as 
well. It changes the action and interaction environments (with other teachers than theirs, with requirements and approaches that are different from what they are used to). They face them with their own limitations and with the chance of overcoming them in an original manner. Breaking the routine and the patterns brings about flexibilization (not only from the physical perspective, but also psychologically and emotionally), which, in turn, increases their abilities to deal with the life challenges at a different level.

Moreover, where students do not have a real image of themselves being somehow protected from the daily challenges of life and society, playing sports could contribute to a better awareness of weaknesses, which is the starting point to make progress in all respects. On the other hand, where students have a low level of self-esteem, the practice of dancesport can contribute to increasing the level of confidence, autonomy and better integration, things that can ultimately lead to an improvement in this aspect.

\section{Limitations of the study}

The study is a starting point in the direction of investigating self-esteem in visually impaired students, but its results cannot be considered general, as the number of subjects is relatively low. Moreover, all subjects are students at the same special school, so we can only talk about some features generated by a certain type of approach to the educational process. Public school students on which the test was applied came from different environments of the country, from different geographical areas with different cultural, social and educational models. Moreover, the degree of impairment and other possible associated conditions were not taken into account in the study.

\section{Applicability of the results}

The present research is only part of a national study on the bio-psycho-social level of visually impaired students, which is designed to constitute a database to facilitate the creation of an adapted and appropriate method of teaching dancesport to visually impaired students. Finally, we intend to investigate whether the practice of dancesport by visually impaired students can positively influence their quality of life.

An individual's level of motor skills is closely related to their degree of autonomy and mental well-being. Therefore, it would be desirable that an increasing number of teachers and coaches specialised in various sports pay more attention to these categories of people and find teaching methods adapted to their needs.

\section{References}

Augestad, L. B. (2017). Self-concept and self-esteem among children and young adults with visual impairment: A systematic review. Cogent Psychology, 4(1). https://doi.org/10.1080/23311908.2017.1319652

Baumeister, R. F., Campbell, J. D., Krueger, J. I., \& Vohs, K. D. (2003). Does high selfesteem cause better performance, interpersonal success, happiness, or healthier lifestyles? Psychological Science in the Public Interest, 4(1), 1-44. 
https://doi.org/10.1111/1529-1006.01431

Binder-Olibrowska, K. W., Wrzesinska, M. A., \& Kocur, J. (2018). Anxiety in persons with visual impairment. Psychiatria Polska, 124, 1-10. https://doi.org/10.12740/PP/OnlineFirst/85408

Bowen, J. (2010). Visual impairment and its impact on self-esteem. British Journal of Visual Impairment, 28(1), 47-56. https://doi.org/10.1177\%2F0264619609349429

Bracken, B. (1995). Handbook of self-concept: Developmental, social, and clinical considerations. John Wiley and Sons Inc.

Brooks, R. B. (1992). Self-esteem during the school years. Its normal development and hazardous decline. Pediatric Clinics of North America, 39(3), 537-550. https://doi.org/10.1016/s0031-3955(16)38343-2

Dawn, R. (2018). Visual impairment and psychosocial development. In Educational achievement and psychosocial transition in visually impaired adolescents (pp. 15-48). Singapore: Springer. https://doi.org/10.1007/978-981-10-6644-3_2

Garaigordobil, M., \& Bernarás, E. (2009). Self-concept, self-esteem, personality traits and psychopathological symptoms in adolescents with and without visual impairment. The Spanish Journal of Psychology, 12(1), 149-160. https://doi.org/10.1017/S1138741600001566

Giese, M., Teigland, C., \& Giessing, J. (2017). Physical activity, body composition, and wellbeing of school children and youths with visual impairments in Germany. British Journal of Visual Impairment, 35(2), 120-129. https://doi.org/10.1177\%2F0264619617689905

Griffin-Shirley, N., \& Nes, S. L. (2005). Self-esteem and empathy in sighted and visually impaired preadolescents. Journal of Visual Impairment \& Blindness, 99(5). https://doi.org/10.1177\%2F0145482X0509900503

Hadidi, M., \& AlKhateeb, J. M. (2013). Loneliness among students with blindness and sighted students in Jordan: A brief report. International Journal of Disability Development and Education, 60(2), 167-172. http://dx.doi.org/10.1080/1034912X.2012.723949

Huurre, T. M. \& Aro, H. M. (2000). The psychosocial well-being of Finnish adolescents with visual impairments versus those with chronic conditions and those with no disabilities. Journal of Visual Impairment \& Blindness, 94(10). https://doi.org/10.1177\%2F0145482X0009401003

Huurre, T. M., Komulainen, E. J., \& Aro, H. M. (1999). Social support and self-esteem among adolescents with visual impairments. Journal of Visual Impairment \& Blindness, 93(1). https://doi.org/10.1177\%2F0145482X9909300104

Kohda, Y., Monma, T., Yamane, M., Mitsui, T., Ando, K., Jesmin, S., \& Takeda, F. (2019). Mental health status and related factors among visually impaired athletes. Journal of Clinical Medicine Research, 11(11), 729-739. https://doi.org/10.14740/jocmr3984

Leary, M. R., \& Baumeister, R. F. (2000). The nature and function of self-esteem: Sociometer theory. Advances in Experimental Social Psychology, 32, 1-62. https://doi.org/10.1016/S0065-2601(00)80003-9

Miklyaeva, A., \& Gorkovaya, A. (2019). Self-esteem of teens with visual impairments as a predictor of hardiness. Social Welfare: Interdisciplinary Approach, 2, 94-105.

DOI: $10.21277 / \mathrm{sw} . v 2 \mathrm{i} 8.331$

Obiakor, F. E., \& Stile, S. W. (1990). The self-concepts of visually impaired and normally sighted middle school children. The Journal of Psychology, 124(2), 199-206. https://doi.org/10.1080/00223980.1990.10543216

Papadopoulos, K. (2014). The impact of individual characteristics in self-esteem and locus of control of young adults with visual impairments. Research in Developmental Disabilities, 35(3), 671-675. https://doi.org/10.1016/j.ridd.2013.12.009 
Papadopoulos, K., \& Papakonstantinou, D. (2019). The impact of friends' social support on depression of young adults with visual impairments. International Journal of Disability Development and Education, 67(5), 484-496. https://doi.org/10.1080/1034912X.2019.1620922

Pelin, F., Mitrache, G., Grigore, Gh., Hidi, I. L., Ciolcă, C., Ghițescu, G. I., \& Badea, D. (2016). Strategie de integrare socială prin sport [Strategy of social integration through sports]. București: Discobolul.

Pinquart, M., \& Pfeiffer, J. P. (2013). Perceived social support in adolescents with and without visual impairment. Research in Developmental Disabilities, 34(11), 4125-4133. https://doi.org/10.1016/j.ridd.2013.08.004

Predoiu, R. (2016). Psihologia sportului. Maximizarea performanței sportive [Sports psychology. Maximisation of sports performance]. Iași: Polirom.

Saigal, S., Lambert, M., Russ, C., \& Hoult, L. (2002). Self-esteem of adolescents who were born prematurely. Pediatrics, 109(3), 429-433. https://doi.org/10.1542/peds.109.3.429

Samson, S. A. (2017). An overview of somatics (body-mind). Approaches in dance therapy. EJOTMAS: Ekpoma Journal of Theatre and Media Arts, 6(1-2). http://dx.doi.org/10.4314/ejotmas.v6i1-2.17

Sánchez-Miguel, P. A., Miguel Leo, F., Amado Alonso, D., Hortigüela-Alcalá, D., TapiaSerrano, M. A., \& De La Cruz Sánchez, E. (2020). Children's physical self-concept and body image according to weight status and physical fitness. Sustainability, 12(3): 782. https://doi.org/10.3390/su12030782

Tołczyk, S., \& Pisula, E. (2019). Self-esteem and coping styles in Polish youths with and without visual impairments. Journal of Visual Impairment \& Blindness, 113(3). https://doi.org/10.1177\%2F0145482X19854903

Țânculescu, L., \& Iliescu, D. (2002). Inventarele de Stimă de Sine Coopersmith [Coopersmith Self-Esteem Inventory]. (Adapted in Romanian). https://www.testcentral.ro/media/csei-issc-pliant-pdf-D71ESM3R.pdf

Were, C. M., Indoshi, F. C., \& Yalo, J. A. (2010). Gender differences in self-concept and academic achievement among visually impaired pupils in Kenya. Educational Research, 1, 246-252. https://www.interesjournals.org/articles/gender-differences-in-selfconceptand-academicachievement-among-visually-impaired-pupils-in-kenya.pdf 